\title{
BackChat
}

\section{Living with reflex anoxic seizure}

$M$ y daughter was 9 months old when attempting to crawl up a stair she slipped and banged her head. She became pale and floppy for just a few seconds and recovered quickly. I wondered if I had imagined it. By the time she could walk and was playing with friends I had almost forgotten the incident. When one of those friends took a toy from her, her response was a typical toddler scream. To my horror this was followed by a sudden collapse to the floor and a few seconds of unconsciousness. I headed straight for my GP who told me he thought this was breath holding. I didn't feel it had been a conscious holding of breath, rather an involuntary collapse, but even though I was a nurse I found myself accepting his assessment-it was a diagnosis I could live with and I didn't want a series of distressing investigations.

The "attacks" as I called them, because they came without warning and Frances was unable to control them, came about once or twice a year until she was 9 years old. I began to see that they had various factors in common. Frances would often be excited when they occurred, as when playing chase with Dad; screaming with delight she suddenly dropped to the floor. She would be pale and her eyes would roll, but after a few seconds she would regain consciousness and start to play again. The faints seemed to go on for an eternity and I always had that dread of her not coming round this time. We tried not to make too much of it for fear of "pathologising" our child. However, sensing our anxiety she would occasionally stay put where she fell in the hope that she could gain more attention by feigning an attack!

Another factor was sudden, unexpected pain. A knock to the head or a tumble from a chair could induce the same response, but not always. It was the unpredictable nature of the condition that made it so bemusing. She would graze her knee one day and be fine, then the same injury another day would have her prostrate on the ground. The attacks began to last a little longer and Fran's limbs would jerk for a few seconds. Once she lost bladder control. My GP still believed that this was breath holding or perhaps a tendency to faint easily. I was told that faints can look like fits. Reassured, if not convinced, we became used to the attacks and felt we could live with them, even without a diagnosis. I found an article in The Guardian about reflex anoxic seizure and was struck by the similarity between this and Frances's problem. My GP had never heard of it but agreed that it could be the cause.

The attacks suddenly stopped and Frances had no more for four years. We began to forget and relax but as she entered puberty she experienced the worst she had ever had. She had slipped at the side of a lake, was not badly hurt, and even began to pick herself up, before falling down again into an apparent fit. After an hour's sleep she was well again but we felt we had to ask more questions. Frances saw a paediatrician, who was not, we were later to discover, a neurologist. She had an EEG and was pronounced epileptic. She was prescribed carbamazepine which we refused. What was the point for one attack in four years? We preferred to wait and see but found we were unable to discuss the possibility of RAS with the consultant. He didn't want to know, and in a busy and understaffed unit our time was obviously up.

I became aware of a frightening condition involving an abnormality of the QT interval. This was similar to RAS in that the sufferer would collapse at times of high excitement. I had joined the RAS support group and knew that the heart does stop during an RAS attack (hence the sudden fall to the ground) but the difference here was that it may not re-start. The "compliant parents" became "pushy parents". We asked to see a cardiologist and Fran had a chest $x$ ray, ECG, 24 hour tracker, and echocardiogram. This was not without complaint from the consultant who had seen "too many of these misdiagnosed epileptics", but by then I was past caring. All we needed to know was that Fran's heart was normal. We saw a neurologist and discovered that the diagnosis of epilepsy was indeed incorrect. Frances did have reflex anoxic seizure, a diagnosis I had suggested nine years before.

With hindsight I wish I had been less accepting of medical opinion and relied
STARS: Syncope Trust And Reflex Anoxic Seizures

Working together with individuals, families and medical professionals to offer support and information on syncopes and reflex anoxic seizures www.stars.org.uk

Faints and funny turns carry a high misdiagnosis rate. Various case series suggest that anything between 10\% and $40 \%$ of children referred to a paediatric neurologist with a diagnosis of epilepsy do not have this disorder. ${ }^{1,2}$ Reflex anoxic seizures are a common piffall. ${ }^{3}$ This month our correspondent describes the shock of receiving a peremptory, and ultimately incorrect, diagnosis.

\section{References}

1. Chadwick D, Smith D. The misdiagnosis of epilepsy. BMJ 2003;324:4956.

2. Metrick ME, Ritter FJ, Gates JC, et al. Non-epileptic events in childhood. Epilepsia 1991;32:322-8.

3. Stephenson JBP. Fits and faints. Clin Dev Med No. 109. London: MacKeith Press, 1990.

a little more on my own. I wish I had insisted that the consultant listen carefully to the pattern of the seizures. No one ever asked me to describe them in detail. If I had we would probably have been saved much unnecessary worry. Frances is 17 and has not had an attack for over two years and we are hoping that she has seen the last of it. She is learning to drive; doing everything in fact that 17 year olds do. Hopefully now that RAS is becoming better known other sufferers will not have to wait so long for a proper diagnosis.

M Warrington

Correspondence to: $\mathrm{Dr} \mathrm{H}$ Marcovitch, Syndication Editor, BMJ Publications; hmarcovitch@btinternet.com 